\title{
Acclimatizing to Digital Natives Environment (DNE) in Developing Nations.
}

\author{
Dr. Williams, Cheta. \\ Dept of Curriculum Studies and Educational Technology Faculty of Education University of Port Harcourt, \\ Nigeria, West Africa.
}

\begin{abstract}
Information and Communication Technology (ICT) has succeeded in producing two sets of generations; Digital Natives (DNs) and Digital Immigrants (DIs) within our school system. This paper therefore takes a turn to highlight on the attributes of these two sets of generations. Also the paper submits that the DNs operate in a learner-centered environment while the Dls, in a teacher-centered environment. However, that the digital era is here with us, the paper thus sues for such measures as; acceptance to innovation and change; DIs training with ICT; ownership of personal PCs by DIs; DIs practicing with ICT; DIs teaching/learning with ICT, amongst others.
\end{abstract}

Key words: conflict, digital immigrants, generations, resolution, savvy.

\section{Introduction}

The later decades of the $20^{\text {th }}$ century to this second decade of the $21^{\text {st }}$ century, have witnessed a new generation of learners, courtesy the increasing presence of ICT in our schools. These learners are the "residents" [1], or the net generation [2] or the born digital generation [3] or, the digital natives [4]. The concept of 'netizens' also goes a long way to confirm this usage. To isolate oneself from the debate on DNs and DIs, these learners as used in this paper are those who were not necessarily born within the periods under review but who have embraced ICT in no small measure. The reasoning is that most persons, though may be born within the period referred, may not be ICT savvy. So, access to ICT is the calibrating parameter here. In other words the period of birth is not the yardstick here but how savvy the learners are in ICT usage, in the submission by [5]. In the [6], they are those learners who see computer as a tool to learn, "with" rather than something we learner "from". In a nutshell, these are learners who appear to be ahead of most of their teachers ICT- wise.

On the other hand the non ICT savvy teachers constitute the second generation who however must function in the DNE of today. This generation is referred to as visitors [1] or digital immigrants [4].The type of training these DIs had may not have provided them with the required access to information and communication technologies (ICTs), that is, if they were even present at that time. That means, most teachers in developing nations may be witnessing the presence of ICTs that never existed in their training days or were they existed; the teachers themselves never interacted with them. It is true that they level of embrace of technology is not the same among nations. While some nations are still at the integration phase, others are at utilization phase and the highly developed ones, at institutionalization phase. The findings by [7] on the percentage of secondary school teachers in relation to their ICT skills conducted in one of the oil rich states of Nigeria showed obvious lack of ICT skills as expressed in the table below.

TABLE: Percentage of secondary school teachers in Rivers State, Nigeria in relation to ICT Skills.

\begin{tabular}{|l|l|l|l|}
\hline $\mathrm{s} / \mathrm{n}$ & \multicolumn{1}{|c|}{ ICT skills } & Status quo & Ideal \\
\hline 1. & Computer hardware & $<20 \%$ & $>60 \%$ \\
\hline 2. & Computer appreciation & $<10 \%$ & $>60 \%$ \\
\hline 3. & Computer application & $<5 \%$ & $>5 \%$ \\
\hline 4. & Regular use of computer & $<12 \%$ & $>60 \%$ \\
\hline 5. & Internet browsing & $<80 \%$ & $>50 \%$ \\
\hline 6. & Internet use & $<80 \%$ & $>50 \%$ \\
\hline 7. & Online project & $<5 \%$ & $>50 \%$ \\
\hline 8. & Computer Based instruction & $<5 \%$ & $>50 \%$ \\
\hline 9. & Computer Assisted Instruction & $<5 \%$ & $>50 \%$ \\
\hline 10. & Videodisc & $<30 \%$ & $>65 \%$ \\
\hline 11. & Satellite Television & $<30 \%$ & $>50 \%$ \\
\hline
\end{tabular}

Source: [7] 
The position today may not show any remarkable difference from the year the study was conducted. The picture above represents the level of teachers that we have, ICT-wise in developing nations like ours. As used in these paper, those in this category consist of those teachers who are not ICT friendly and so fail to explore the potentials of ICT in the cause of teaching and learning. But then, one, thing is obvious a mutual coexistence of these two generations is inevitable in a school setting of today that is witnessing a serious transformating in terms of the conventional activities that the school is known for. Also there is a serious paradigm shift in the conventional role of both the learner and the teacher who have come to assume new role and responsibility. However, the resolution of the conflict that exists between these two generations as a result of their ICT differences will go a long way in making the advocacy for ICT integration, utilization and institutionalization a reality.

\section{The digital natives and their characteristics.}

The digital natives as used in this context are associated with these attributes:

$>$ spend more time with ICT devices and tools

$>$ prefer graphics or visuals to texts

$>$ function best when networked

$>$ access information faster and with ease

$>$ computer savvy

$>$ play games and watch animations

$>$ handle, dismantle and assemble ICT devices and tools

$>$ in short, are technophilic

\section{The digital immigrants and their characteristics}

On the other hand, these foreigners are associated with the following attributes.

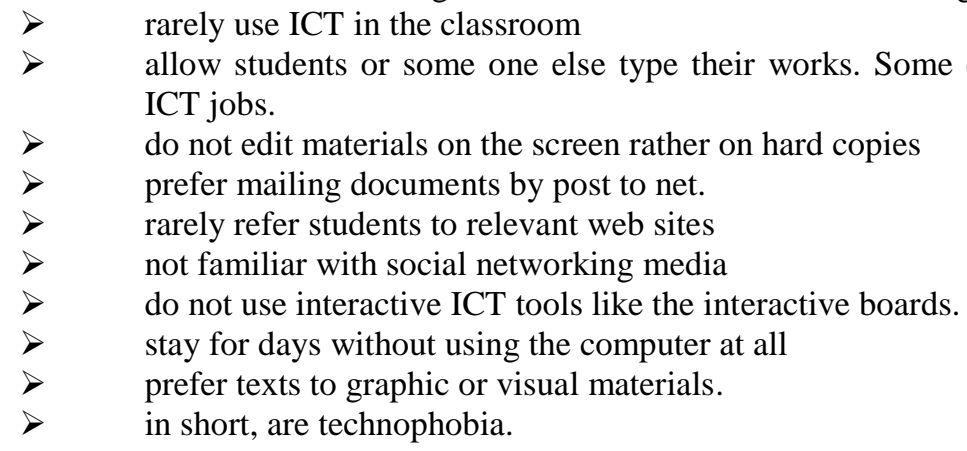

\section{DNE: A learner-centered environment (LCE)}

The digital native environment by all assessment can be described as a learner-centered environment. It is an environment that key roles of the digital natives have changed. In this environment, DIs are no longer passively waiting for the teacher to give direction and information rather they are actively searching for needed information and learning experience, determining what is needed, and seeking ways to attain it. They are not always playing the role of learners rather participate at times as experts and knowledge providers. In the words of [8] they are not always following given procedures rather desire to explore, discover and create unique solutions to learning problems. Hence they do not view the teacher as the one who has all the answers, rather view the teacher as a resource person, model and helper who should encourage explorations.

Teacher- students

In a DNE, teacher- learner relationship can be depicted as shown below. 


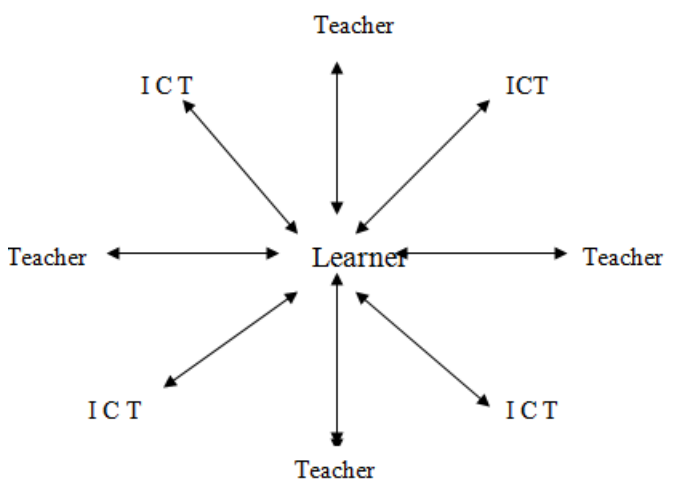

Fig 1. dne- teacher- learner relationship

The fig. above depicts the learner as the hub of the learning wheel and the centre of all activities. The active learner is central in the DNE. Hence all learning activities revolve around, the learner. In the same vein, knowledge and information are no unidirectional issues in his environment. Communication in the DNE, conforms to the two - way rule and feedback is a convention. The presence of both the teacher and the ICT is a tenet of this environment. The learner interacts with the ICT in particular, without necessary waiting for the teacher who perhaps assumes the role of a facilitator rather than the primary source of knowledge.

In a nutshell, the DIs is no longer passive recipients of information rather are active participants in the learning process. They do not wait to reproduce knowledge rather produce and share knowledge, participating at times as expects as already shared. So rather than see learning as a solitary activity, they see it as a collaborative thing with others or peers, so they make adequate use of social networking media amongst others.

In this learner-centered environment as reported by [9] classroom activities rather than become didactic, become interactive, teacher's role rather than that of facts teller, becomes collaborative. In the same vein, learners' instructional emphasis rather than facts and memorization becomes relationship, inquiry and invention, and technology used rather than for mere drill and practice, becomes communication, access, collaboration and expression.

This picture above has in no small measure influenced the DIs and the only way they are function effectively in this knowledge - based economy is by ensuring that this sharp conflict or gap is bridged.

\section{DIE: A teacher -centered environment (T C E).}

Contrast to the position above, the DIs environment is a teacher-centered environment. This environment accords the teacher a conspicuous position as the sole and only source of knowledge and a dispenser of knowledge. The teacher imparts knowledge, skills and values and dominates the entire class session [10]

In the words of [8] the teacher is viewed as the content expert and source of all the answers, the primary source of knowledge of information who continually directs to students; always asking questions and controlling the focus of students' learning. The same authors add that the teachers in this environment direct students through preset step-by-step exercises so that all achieve similar conclusions.

In this DIE, the teacher- learner's relationship can be illustrated as shown below

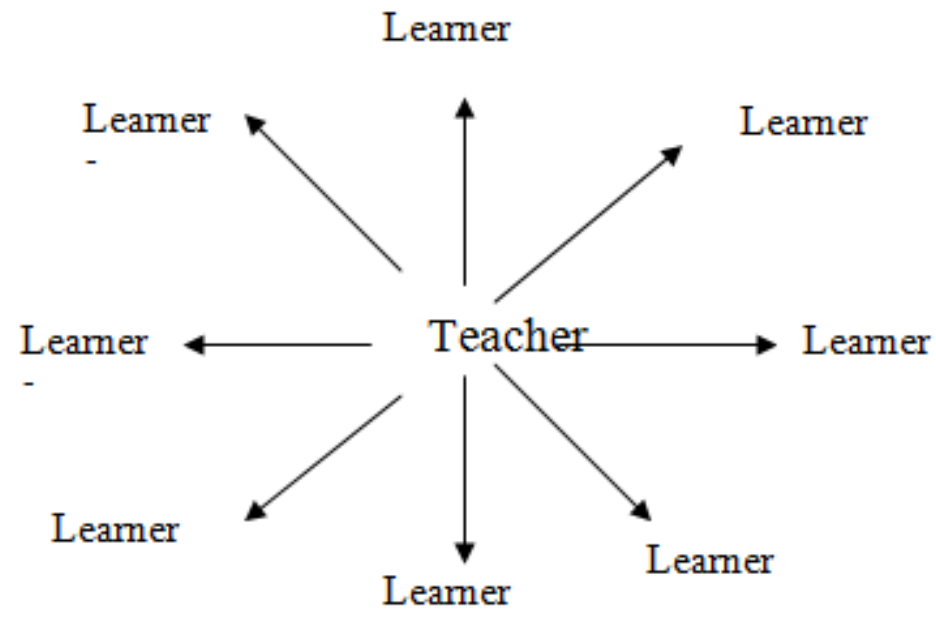

Fig 2. die - teacher - learner relationship 
In this environment, the teacher is the centre stage of all activities. There is absence of ICT or where they exist, their roles are never explored. In this environment, communication is a one way process as information and knowledge come from a mono- source, the DI.

The view of the learning process in this environment is that learning is a hard and tedious process and is based on the deficit model of the students. It also has it that learning is a process of information transfer and reception. In the words of [9] learning with this lens, is seen as an individual or solitary process, a linear process that is facilitated by breaking contents/instructions into small isolated units. This is the basis why the teacher assumes that learners are still empty slates where knowledge is to be deposited. Hence in this environment, the concept of knowledge is accumulation of facts and quantity rather than quality and demonstration of success is norm referenced rather than quality of understanding, and promoting drill and practice only in the use of technology as already shared.

\section{Resolving the conflict between the two generations}

It is obvious that ICT is moving so fast and the presence is heavily felt in our institutions, so that digital immigrants have no option than to flow with the demands of the age, hence the following approaches are essential.

$>$ DIs should accept to this simple innovation and change. ICT is an innovation that has come to be, so DIs should not be associated with the usual lukewarm, indifferent and apathetic attitude to changes and innovations, DIs should learn to overcome their technophobia trait in this $21^{\text {st }}$ century. The advocacy for ICT integration, utilization and institutionalization would only be real where the passion for ICT by DIs educators is real.

$>$ DIs should train with ICT. Personal development is a norm in this instance. The reasoning is that the education most of the DIs had may not have afforded them the opportunity to the daily use of ICT. So the DI should be undergoing personal training on regular basis just as knowledge of ICT continues to grow and expand on daily basis. Regular attendance and active participation in ICT workshops, not talkshops is advocated in this paper.

$>$ DIs as a matter of policy should own their personal PCs. A laptop is a must in this direction. In a non institionalized ICT environment, every DIs should own a personal laptop and a modem for online access. That means an educator that does not own one can not belong to this new order. A laptop with modem should be a handy device at the disposal of every DI to cope in this new environment. The reasoning is that one can only practice with, train with and be acquainted with a device or tool that is available, and not in a vacuum. In other words, there must be an available pool for one to learn how to swim.

$>$ DIs should practice with ICT. A popular belief has it that practice makes perfect, so the DIs should be practicing with ICT as often as possible, ICT tools, devices and accessories. Though there are different kinds of ICTs, DIs should practice with the ones that apply in the immediate academic environment where they find themselves. It is obvious that one of the basic principles of media utilization is practice, so it should be explored to its fullest if one must cope in the new learning environment [11]

$>$ DIs should teach/learn using ICT. ICT should be part and parcel of their instructional process. Websites that would enhance their teaching should be explored and ICT- based lessons should be incorporated in their instructions. The DIs should appreciate the potentials of ICT in terms of online instructions, research and learning in general. It is very unfortunate that many only use ICT to access materials in the net for writings but hardly integrate them in teaching proper. That is the reason why they do the talking from the beginning to the end of the class. This should not be the case. The potentials of ICT should be explored in our teaching to also promote wide knowledge access.

$>$ DIs should realize that they exist in a new learning environment. Yester years, it was knowledge, skills and values impartation, today it is knowledge, skills and values acquisition. Learners are no longer empty slates to be spoon fed rather they should be assisted to discover their potentials. Educational products that are creative minds and imaginative learners should be the focus, than learners that cannot solve real life problems. So the emphasis should be on deep learning rather than shallow learning, multiple sources of knowledge rather than a mono-source, and assessment should go beyond paper and pencil test to authentic, genuine and real life assessment. It is only in this wise that learning can be said to be meaningful.

\section{Conclusion}

Adaptation or acclimatization by DIs to the current wave of ICT in our schools is cardinal in the net age of today. Learning has changed; the role of both the learner and the teacher has changed equally and in no small measure. The DIs have some duties to perform, they must accept change, own their PCs, participate vigorously in capacity development programmes, practice with ICT, use ICT and appreciate the very fact that a new learning environment has come to be. These approaches are sure measures of closing this generational gap between the DNs and the DIs. 


\section{References}

[1]. D.S. White, and A. Le Cornu.. Visitors and residents: A new typology for online engagement. First Monday 16 (9) 2011 ,5.

[2]. C. Jones, and B Shao,. The net generation and digital natives: implications for higher education. Higher Education Academy New York: UK, 2011.

[3]. J. Spear, People born digital. A paper presented at Zeitgeist. Europe, 2007.

[4]. M. Prensky, Digital natives, digital immigrants. On The Horizon 9 (5) 2001, 1-6.

[5]. S. Benneth, K Maton, and L Kelvin, The digital native debate: A critical review of the evidence. British Journal of Educational Technology 39 (5), 2008, 775-786.

[6]. D.H Jonassem, Computers as mindtools for schools: Engaging critical thinking. Columbus: Prentice Hal, 2000.

[7]. C. Williams, The integration of information technology in our schools via the needs assessment approach (NAA). Nigerian Journal of Research and Production, 7. (3) 2005, 59-63.

[8]. J.J, Newby, D.A Stepich, J.D. Lehman, and J.D Russell,. Educational technology for teaching and learning (3 ${ }^{\text {rd }}$. ed.). New Jersey: Prentice Hall, 2006.

[9]. P. Resta. (Ed) Information and communication technology in teacher Education: A planning guide. Russia: UNESCO, 2002.

[10]. C. Williams, Principles and methods of teaching and learning: A contextual approach. Omoku: Thompchims Press and Computer Ser. 2005.

[11]. R Heinich,; M Molenda,. And J.D. Russell, Instructional media and the new technologies of instruction, (3 ${ }^{\text {rd }}$ ed.). New York: Macmillan, 1989. 